\title{
ANALISA PENGENDALI HYBRID SLIDING MODE CONTROL DAN PID UNTUK MENGENDALIKAN CONCENTRATION PADA ISOTHERMAL CONTINUOUS STIRRED TANK REACTOR (CSTR)
}

\author{
Ahmad Faizal $^{1}$, Dian Mursyitah ${ }^{2}$, Ewi Ismaredah ${ }^{3}$, Muhammad Ikhsyan $^{4}$ \\ ${ }^{1,2,3,4}$ Jurusan Teknik Elektro, Fakultas Sains Dan Teknologi UIN Suska Riau \\ Jl.HR. Soebrantas No. 155 Simpang Baru, Panam, Pekanbaru, 28293 \\ Email.ahmad.faizal@uin-suska.ac.id,dmursyitah@uin-suska.ac.id, ewi.ismaredah@uin-suska.ac.id, \\ Muhammad.ikhsyan13@gmail.com
}

\begin{abstract}
Systems in industry often occur in performance or desired performance. One of them isothermal CSTR system where the system has not been able to work according to the desired set point $1 \mathrm{~g} . \mathrm{mol} /$ litter, to achieve the set point then used the controller Sliding Mode Control in Hybrid with PID in identification with FOPDT method to lower the value steady state error From the controller obtained results where the Sliding Mode Control Hybrid PID is able to not achieve set point value 1 g.mol / litter with ts $=3.0446$ seconds
\end{abstract}

Keywords :FOPDT, Isothermal CSTR (Continuous Stirred Tank Reactor)PID, Sliding Mode Control.

\section{INTISARI}

Sistem di industri sering terjadi kesalahan dalam mencapai kinerja atau performansi yang diinginkan. Salah satunya pada sistem isothermal CSTR dimana sistem ini belum mampu bekerja sesuai set point yang diinginkan 1 g.mol/litter, untuk mencapai set point maka digunakan pengendali Sliding Mode Control yang di Hybrid dengan PID yang di identifikasi dengan metode FOPDT untuk menurunkan nilai error steady state. Dari pengendali tersebut didapat hasil hasil dimana Sliding Mode Control Hybrid PID belum mampu mencapai nilai set point 1 g.mol/litter dengan $\mathrm{t}=3.0446$ detik

Kata kunci :FOPDT ,Isothermal CSTR (Continuous Stirred Tank Reactor) PID, Sliding Mode Control.

\section{PENDAHULUAN}

Salah satu bentuk reactor ialah isothermal CSTR dimana isothermal CSTR adalah sejenis CSTR yang ada dan beroperasi pada suhu konstan. Volumenya juga diasumsikan konstan[2].

Sudah ada beberapa penelitian yang terkait dengan sistem Isothermal Continuous Stirred Tank Reactor (CSTR) ini dimana sistem Isothermal Continuous Stirred Tank Reactor (CSTR) ini belum mampu untuk mencapai set point yang diinginkan sehingga diperlukan pengendali agar error steady state yang terjadi dapat diminimalisir. Berdasarkan penilitian yang terkait, penulis tertarik untuk melakukan sebuah penelitian dengan menggunakan pengendali PID yang dinilai dapat membangkitkan rise time serta dapat mengurangi settling time [3], dengan pengendali Sliding Mode Control (SMC) yang dinilai lebih kuat terhadap perubahan dan gangguan set point [4].

Dimana tujuan utama penggunaan pengendali sliding mode adalah untuk memaksa dan membatasi variabel yang dikendalikan berada pada permukaan luncur yang dirancang dan menjaganya agar dapat tetap berada pada keadaan yang diinginkan [5]. 


\section{TINJAUAN PUSTAKA}

A. Pengendali Sliding Mode

Pengendali sliding mode merupakan sebuah kendali umpan balik pensaklaran berkecepatan tinggi (high speed switching feedback control) yang efektif dan kokoh dalam mengendalikan sistem linier maupun non linier [7].

Pengendali sliding mode terkenal karena kekokohannya karena pengendali ini menyediakan sebuah metode perancangan sistem yang tidak peka terhadap ketidakpastian parameter lingkungan dan gangguan dari luar [7], yang di definisiakan dengan persamaan sebagai berikut.

a. Sistem dinamis

$$
x^{(n)}(t)=f(x, t)+b(x, t) \cdot u+d(t)
$$

Dimana $u$ control input, $x$ merupakan vector keadaan, $f(x, t)$ dan $b(x, t)$ berupa fungsi terbatas, $d(t)$ gangguan eksternal. Jika $x_{d}$ merupakan $x$ yang diinginkan, maka tracking error-nyadapat dinyatakan dengan [10].

$e(t)=x(t)-x_{d}(t)$

b. Fungsi Switching

Fungsi Switching yaitu permukaan $S(x, t)$ di dalam ruang keadaan $R^{n}$, memenuhi persamaan [10].

$$
S(x, t)=\left(\frac{d}{d t}+\lambda\right)^{(n-1)} e
$$

c. Permukaan Sliding

Permukaan sliding (sliding surface) merupakan persamaan yang memenuhi $S(x, t)=0$

\section{d. Konidisi Sliding}

Besar nilai control input pada SMC bergantung pada nilai $\mathrm{S}$, sehingga memenuhi pertidaksamaan yang disebut kondisi sliding. Kondisi tersebut ditulis dalam bentuk sebagai berikut.

$$
S \dot{S}<0 \text { atau } \dot{S} \operatorname{sgn}(S) \leq-\eta
$$

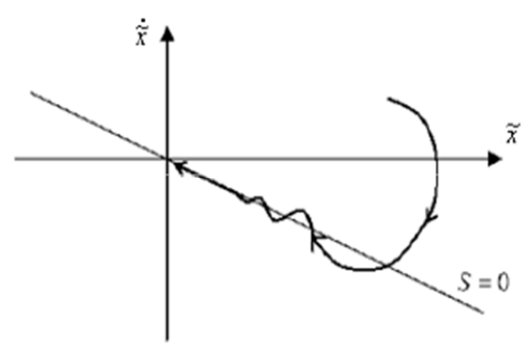

Gambar 1. Kondisi Sliding [10]

B. Pengendali Proporsional Integral Derivative (PID)

Pengendali PID merupakan pengendali otomatis yang yang merupakan gabungan dari pengendali Proporsional, Integral, dan Derivatif. Bentuk umum dari pengendali PID sebagaiberikut:

$$
u(t)=K_{p} e(t)+K_{i} \int_{0}^{t} e(t) d t+K_{d} \frac{d e}{d t}
$$

\section{Modeling \& Ishotermal CSTR}

Isotermal CSTR adalah sejenis CSTR yang ada beroperasi pada suhu konstan. Volumenya juga di asumsikan konstan, Skema reaksi terdiri dari reaksi ireversibel aliran umpan hanya berisi komponen $\mathrm{A}[2]$.

Adapun jenis cairan yang digunakan pada proses penelitian ini diantaranya ialah sebagai berikut Cyclopentadine, Cyclopentenol, Cyclopentanediol, Dicyclopentadiene [2]. Pada kondisi isotermal atau suhu tetap, suhu umpan sama dengan suhu larutan di dalam reaktor maupun suhu larutan keluar reaktor [12].

Isotermal CSTR memiliki reaksi berikut skema yang disebut reaksi Van de Vusse [2].

$$
A \stackrel{k_{1}}{\rightarrow} B \stackrel{k_{2}}{\rightarrow} C 2 A \stackrel{k_{3}}{\rightarrow} D
$$


Dari skema diatas ditunjuk tahapan tahapan terhadap laju molaritasnya, dari skema tersebut didapatlah konstantanya sebagai berikut [2]:

$\mathrm{K}_{1}=50 \mathrm{~h}^{-1}=0.83 \mathrm{~min}^{-1}$

$\mathrm{K}_{2}=100 \mathrm{~h}^{-1}=1.66 \mathrm{~min}^{-1}$

$\mathrm{K}_{3}=100 \mathrm{moll}^{-1} \mathrm{~h}^{-1}=0.166 \mathrm{moll}^{-1} \mathrm{~min}^{-1}$

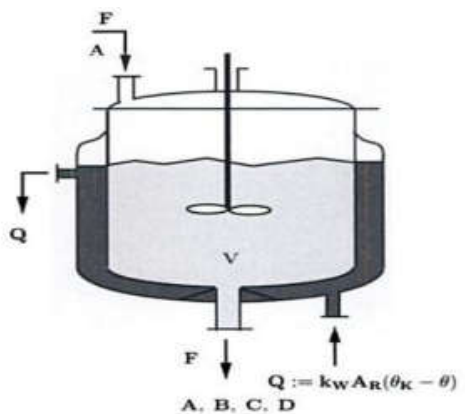

Gambar 2. Representasi skema pada reaktor

Konsentrasi umpan pada steady state adalah $C_{A f s}=10 \mathrm{gmoll}^{-1}$

Persamaan untuk keseimbangan

keseluruhan material yang digunakan [2].

$\frac{d(V \rho)}{d t}=F{ }_{i} \rho-F \rho$

Jadi

$F=F_{i}$

Komponen keseimbangan material bisa juga menggunakan [2]

$\frac{d\left(V C_{A}\right)}{d t}=F\left(C_{A f}-C_{A}\right)-V k_{1} C_{A}-V k_{3} C_{A}^{2}$

Untuk menyederhanakan persamaan (6) kita dapat menggunakan Persamaan yang ada pada (7) berikut adalah persamaan untuk setiap komponen kesetimbangan materialnya [2].

$\frac{d C_{A}}{d t}=\frac{F}{V}\left(C_{A f}-C_{A}\right)-r_{A}$

$\frac{d C_{B}}{d t}=-\frac{F}{V} C_{B}+k_{1} C_{A}-r_{B}$

Tingkat pembentukan molar untuk setiap komponen (per unit volume) sebagai berikut [2].

$$
\begin{aligned}
& r_{A}=-k_{1} C_{A}-k_{3} C_{A}^{2} \\
& r_{B}=k_{1} C_{A}-k_{2} C_{B}
\end{aligned}
$$

Sementara untuk konsentrasi steady state A dan $B$ didefinisikan dengan persamaan sebagai berikut [2].

$C_{A S}=\frac{-\left(k_{1}+\frac{F_{S}}{V}\right)}{2 k_{3}}+\frac{\sqrt{\left(k_{1}+\frac{F_{S}}{V}\right)^{2}+4 k_{3} \frac{F_{S}}{V} C_{A f S}}}{2 k_{3}}$

$C_{B S}=\frac{k_{1} C_{A S}}{\frac{F_{S}}{V}+k_{2}}$

Keadaan ruang model linier direpresentasikan sebagai berikut [2]

$x=A x+B u$

$Y=C x+D u$

Untuk variabel state di representasikan dengan matriks A sebagai berikut [2]

$x=\left[\begin{array}{ll}C_{A} & -C_{A S} \\ C_{B} & -C_{B S}\end{array}\right]$

Untuk variabel output di represetasikan dengan matriks B sebagai berikut [2]

$y=\left[\begin{array}{ll}C_{A} & -C_{A S} \\ C_{B} & -C_{B S}\end{array}\right]$

Variabel input di representasikan sebagai berikut [2]

$u=\left[\begin{array}{ll}\frac{F}{V} & -\frac{F_{S}}{V}\end{array}\right]$

Dua persamaan fungsional dinamis direpresentasikan sebagai [2]

$\frac{d C_{A}}{d t}=f_{1}\left(C_{A}, C_{B}, \frac{F}{V}\right)=\frac{F}{V}\left(C_{A f}-C_{A}\right)-k_{1} C_{A}-k_{3} C_{A}^{2}(17)$

$\frac{d C_{B}}{d t}=f_{2}\left(C_{A}, C_{B}, \frac{F}{V}\right)=-\frac{F}{V} C_{B}+k_{1} C_{A}-k_{2} C_{B}$

Elemen ruang pada state space Matriks A ditentukan oleh

$$
A_{i j}=\left.\frac{\partial f_{i}}{\partial x_{j}}\right|_{X_{s}, U_{s}}
$$

$A_{11}=\left.\frac{\partial f_{1}}{\partial x_{2}}\right|_{X_{s}, U_{s}}=\left.\frac{\partial f_{1}}{\partial C_{A}}\right|_{X_{s}, U_{S}}=-\frac{F_{s}}{V}-k_{1}-2 k_{3} C_{A S}$

$A_{12}=\left.\frac{\partial f_{1}}{\partial x_{2}}\right|_{X_{s}, U_{s}}=\left.\frac{\partial f_{1}}{\partial C_{B}}\right|_{X_{s}, U_{S}}=0$ 


$$
\begin{aligned}
& A_{21}=\left.\frac{\partial f_{2}}{\partial x_{1}}\right|_{X_{s}, U_{s}}=\left.\frac{\partial f_{2}}{\partial C_{A}}\right|_{X_{s}, U_{S}}=k_{1} \\
& A_{22}=\left.\frac{\partial f_{2}}{\partial x_{2}}\right|_{X_{s}, U_{s}}=\left.\frac{\partial f_{2}}{\partial C_{B}}\right|_{X_{S}, U_{S}}=-\frac{F_{S}}{V}-k_{2} \\
& A=\left[\begin{array}{ll}
A_{11} & A_{12} \\
A_{21} & A_{22}
\end{array}\right]=\left[\begin{array}{cc}
-\frac{F_{S}}{V}-k_{1}-2 k_{3} C_{A S} & 0 \\
k_{1} & \frac{F_{S}}{V}-k_{2}
\end{array}\right]
\end{aligned}
$$

Elemen ruang pada state space Matriks B ditentukan oleh

$$
\begin{aligned}
& B_{i j}=\left.\frac{\partial f_{i}}{\partial u_{j}}\right|_{X_{s}, U_{s}} \\
& B_{12}=\left.\frac{\partial_{1}}{\partial u_{2}}\right|_{X_{s}, U_{S}}=\left.\frac{\partial_{1}}{\left(\frac{F_{s}}{V}\right)}\right|_{X_{s} U_{s}}=\frac{F_{s}}{V} \\
& B_{21}=\left.\frac{\partial f_{2}}{\partial u_{1}}\right|_{X_{s}, U_{S}}=\left.\frac{\partial f_{2}}{\partial\left(\frac{F}{V}\right)}\right|_{X_{S} U_{S}}=-C_{B s} \\
& B_{22}=\left.\frac{\partial f_{2}}{\partial u_{2}}\right|_{X_{S}, U_{S}}=\left.\frac{\partial f_{2}}{\partial\left(-\frac{F_{S}}{V}\right)}\right|_{X_{S} U_{S}}=0 \\
& B=\left[\begin{array}{ll}
B_{11} & B_{12} \\
B_{21} & B_{22}
\end{array}\right]=\left[\begin{array}{cc}
C_{A f s}-C_{A S} & \frac{F_{S}}{V} \\
-C_{B S} & 0
\end{array}\right]
\end{aligned}
$$

Dari matriks A danmatriks B di atas di dapatlah model ruang State Space yang di representasikan sebagai berikut

$$
\begin{aligned}
& A=\left[\begin{array}{cc}
-\frac{F_{S}}{V}-k_{1}-2 k_{3} C_{A S} & 0 \\
k_{1} & \frac{F_{S}}{V}-k_{2}
\end{array}\right] \\
& B=\left[\begin{array}{cc}
C_{A f s}-C_{A S} & \frac{F_{S}}{V} \\
-C_{B S} & 0
\end{array}\right] \\
& C=\left[\begin{array}{ll}
0 & 1
\end{array}\right] \\
& D=\left[\begin{array}{ll}
0 & 0
\end{array}\right]
\end{aligned}
$$

Selanjutnya mengubah model state space ke

\begin{tabular}{|c|c|c|c|}
\hline No & Parameter & simbol & Nilai \\
\hline 1 & Steady state feed concentration & $C_{40}$ & $10 \mathrm{~g} \mathrm{moll}^{-1}$ \\
\hline 2 & Steady state concentration of A & $C_{A S}$ & $3 \mathrm{~g} \mathrm{moll}^{-1}$ \\
\hline 3 & Steady State Concentration of B & $C_{B S}$ & $1.117 \mathrm{~g} \mathrm{moll}^{-}$ \\
\hline 4 & $\begin{array}{l}\text { Rate Constant for } \\
A \rightarrow B\end{array}$ & $k_{1}$ & $0.83 \mathrm{~min}^{-1}$ \\
\hline 5 & Rate Constant for $B \rightarrow C$ & $k_{2}$ & $1.66 \mathrm{~min}^{-1}$ \\
\hline 6 & Rate Constant for $2 A \rightarrow D$ & $k_{3}$ & $\begin{array}{l}0.166 \mathrm{moll}^{-1} \\
\mathrm{~min}^{-1}\end{array}$ \\
\hline 7 & & $\frac{F_{s}}{V}$ & $0.5714 \mathrm{~min}^{-1}$ \\
\hline
\end{tabular}
transfer function

$$
G(s)=C(s I-A)^{-1} B
$$

$$
\begin{aligned}
& G_{p}=\frac{-1.117 s+3.1472}{s^{2}+4.6429 s+5.3821} \\
& G_{d}=\frac{0.4762}{s^{2}+4.6429 s+5.3821}
\end{aligned}
$$

Dimana persamaan (36) adalah fungsi alih pada prosess isothermal CSTR dan (37) adalah beban pada fungsi alih .

Tabel 1. Parameter Proses Ishotermal CSTR [2]

III. METODE PENELITIAN

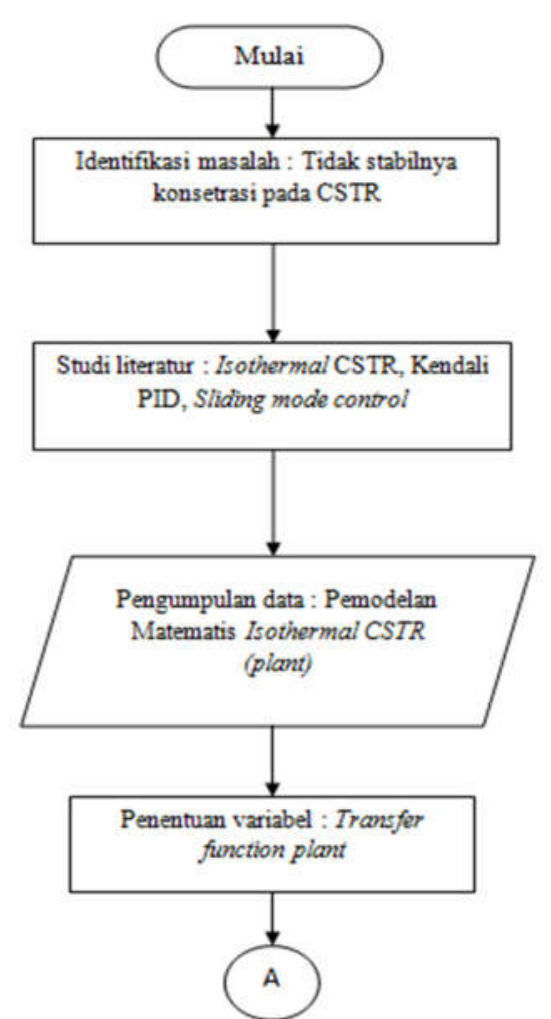




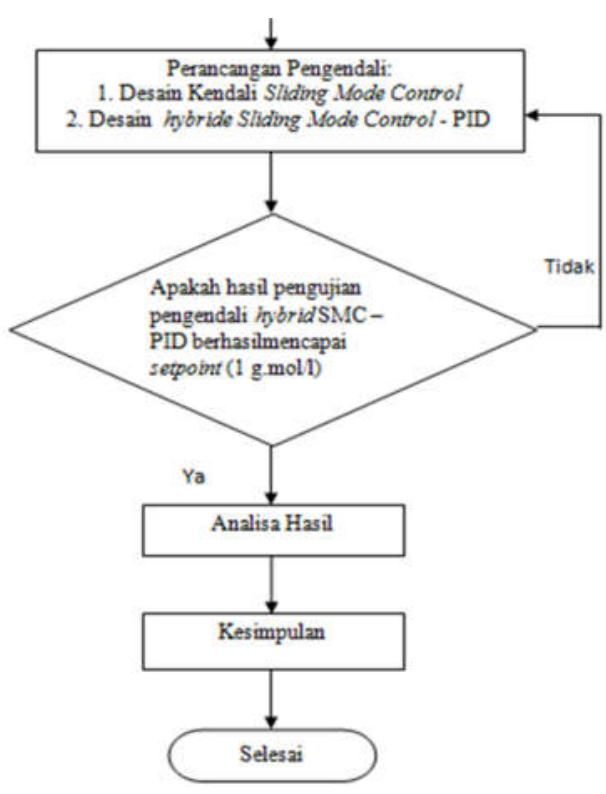

Gambar 3.Flow Chart Penelitian

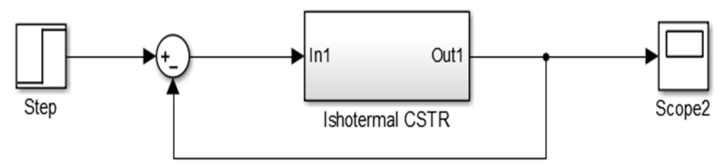

Gambar 4. Blok Sistem Isothermal CSTR

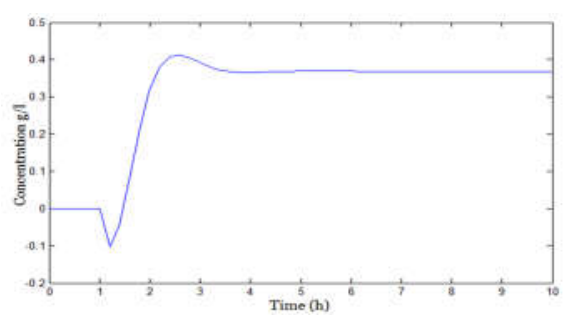

Gambar 5. Respon konsentrasi simulasi open loop Isothermal CSTR

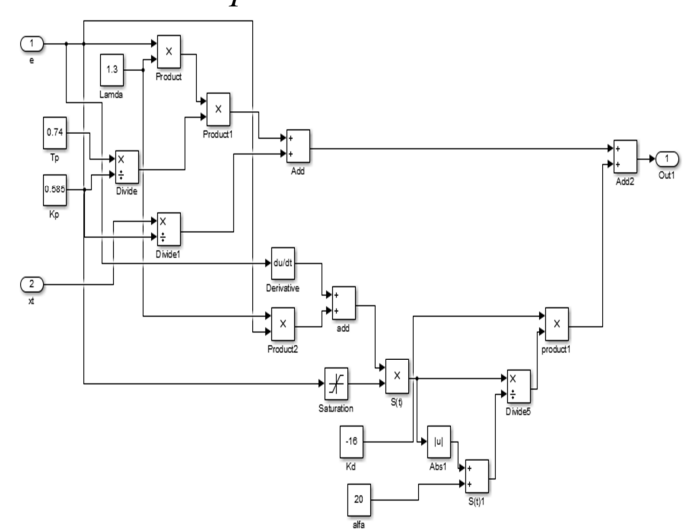

Gambar 6. Pemodelan Blok Simulink Dari Persamaan Utotal

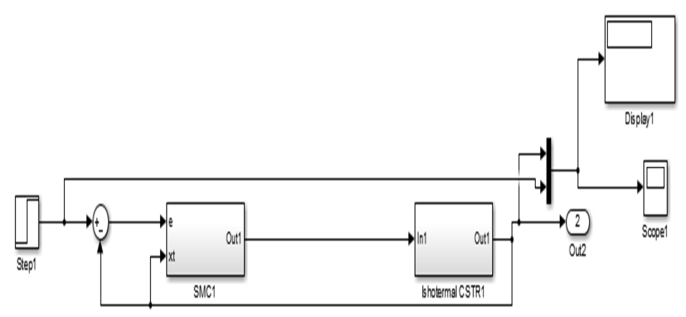

Gambar 7. Pemodelan Sliding Mode Control Pada Plant Sistem Isothermal CSTR

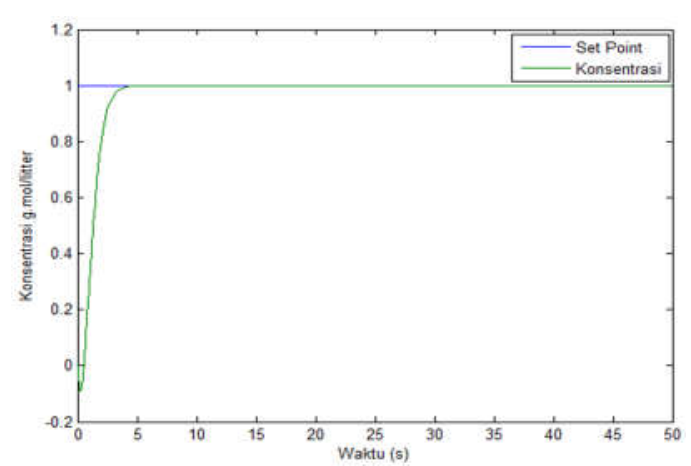

Gambar 8. Grafik Sistem Isothermal CSTR dengan Pengendali Sliding Mode Control Sliding Mode Control Hybrid PID

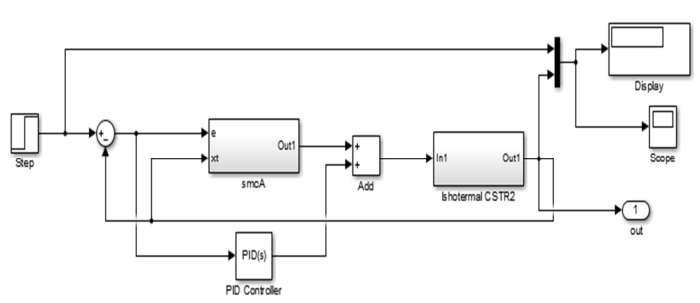

Gambar 9.PemodelanHybrid Sliding Mode ControlDan PID

Dari pemodelan blok sistem Simulink diatas didapatlah keluaran dan bentuk grafik sebagai berikut.

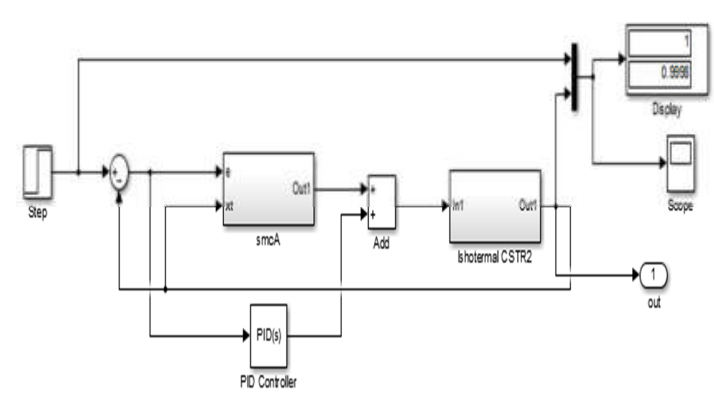

Gambar 10.KeluaranPemodelanHybrid Sliding Mode ControlDan PID 
Dari model blok system diatas dapat dilihat bentuk grafik yang didapat pada variable scope

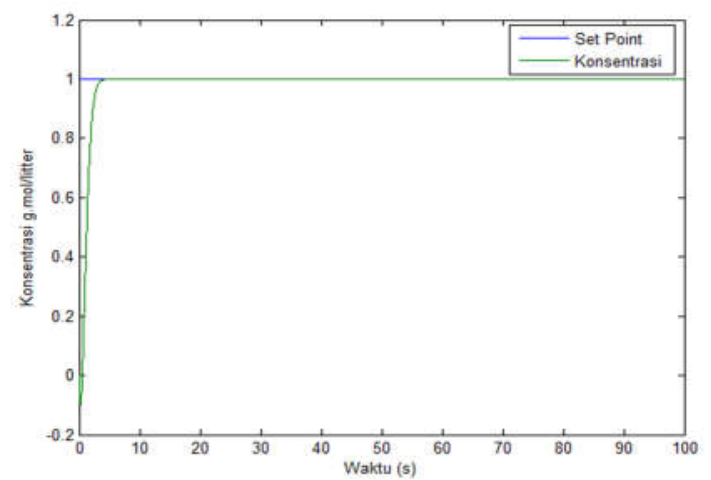

Gambar 11.GrafikSistemIsothermal CSTRdenganPengendaliHybrid Sliding Mode Control Dan PID

Dari hasil grafik respon keluaran seluruhnya didapatlah nilai respon transiennya pada tabel sebagai berikut

Tabel 2. Hasil Analisa Time Respons Sistem

\begin{tabular}{|c|c|c|}
\hline \multirow{2}{*}{} & \multicolumn{2}{|c|}{ Pengendali } \\
\cline { 2 - 3 } & SMC & S.MC Hybrid PID \\
\hline $\mathrm{t}$ & 1.5799 detik & 1.5223 detik \\
\hline $\mathrm{ts}$ & 3.1598 detik & 3.0446 detik \\
\hline $\mathrm{tr}$ & 4.652 detik & 4.48 detik \\
\hline $\mathrm{td}$ & 3.925 detik & 3.78 detik \\
\hline ess & 0.0004 g.mollitter & 0.0002 g.mol litter \\
\hline
\end{tabular}

IV. KESIMPULAN \& SARAN Pada penelitian ini pengendali hybrid sliding mode control danPID belum mencapai nilai set point yang di inginkan yaitu 1 g.mol/litter dengan waktu tunak/settling time 3.0446detik dimana dengan nilai error steady state yang lebih kecil yaitu 0.0002 g.mol/litter, sementara pada pengendali sliding mode control mengalami error steady state sebesar 0.0004 g.mol/litter dengan waktu tunak/settling time 3.1598 detik.

\section{REFERENSI}

[1] Wikipedia. 2017. Reaktor. https://id.wikipedia.org/wiki/Reakt or (Diakses Senin 4 Desember 2017)

[2] Vishal Vishnoi, Subhransu Padhee, Gagandeep Kaur. 2012. Controller Performance Evaluation for Concentration Control of Isothermal Continuous Stirred Tank Reactor. International journal of Scientific and Research Publications. Volume 2, issue 6.

[3] Farhad Aslam dan Gagan deep Kaur.2011.Comparative Analysis of Conventional, P, PI, PID and Fuzzy Logic Controllers for the Efficient Control of Concentration in CSTR.International Journal of Computer Applications (0975 8887) Volume 17- No.6, March 2011.

[4] H. J. Tham, K. B. Ramachandran, and M. A. Hussain. 2003. Sliding Mode Control for a Continuous Bioreactor. Department of Chemical Engineering, University of Malaya, Kuala Lumpur 50603, Malaysia.

[5] Boby Dwi Apriyadi. 2017. Perancangan Sliding Mode Controller Untuk Sistem Pengaturan Level dan Flow Dengan Metode Decoupling Pada Plant Coupled Tanks. Jurusan Teknik Elektro Institut Teknologi Sepuluh Nopember ,Surabaya, Indonesia.

[6] R. A. Decarlodan H. Z. Stainslaw., Variabel Structure Control of Nonlinear Multivariabel System: A Tutorial. 
Proceedings Of The IEEE. Vol. 76(3).212-232. 1988.

[7] Slotine, J-J.E., Weiping Li. Applied Nonlinear Control. Prentice-Hall International, Inc.Hal. 276-284.1991.

[8] Sahat Pak pahan. 1988. Kontrol otomatik: teori dan penerapan. Erlangga.

[9] Palm, R., Driankov, D., dan Hellendoorn, H. 1997. Model Based Fuzzy Control: Fuzzy Gain Schedulers and Sliding Mode Fuzzy Controllers. Berlin: Springer-Verlag.

[10] Wawan Ismanto. Perancangan dan Simulasi Sistem Kontrol Posisi Pada Panel Surya Dengan Menggunakan Metode Fuzzy Sliding Mode Control (FSMC). Teknologi Sepuluh Nopember ,Surabaya, Indonesia.

[11] Marya ningsih, B.Herawan Hayadi, Eko Suryana.2013. Implementasi Logika Fuzzy Dalam Perancangan Sistem Pemngambilan Keputusan Usulan Pemasangan Listrik Berdasarkan Distribusi Beban Listrik.Universitas Dehasen Bengkulu

[12] Sumarni, Ani Purwanti, Pemanfaatan Metode NewtonRaphson Dalam Perancangan Alir Tangki Berpengaduk. Institut Sains \& Teknologi AKPRIND Yogyakarta, 2009.

[13] Rzal Rivaldi. 2017. Tuning Kontrol PID Pada Ole Process Control (OPC) Server Dan Distributed Control System (DCS). Institut Teknologi Sepuluh Nopember Indonesia.
[14] Oscar Camacho, Ruben Rojas. An Approach Of Sliding Mode Control For Deadtime Systems. Universidad de los andes. Venezuela.

[15] Ogata, Katsuhiko. Modern Control Engineering, 4th edition. New Jersey : Prentice Hall, 2002

[16] Arsyad. Arfan. 2013.Matlab. 'http://arfanultras1999.blogspot.co .id/2013/03/normal-0-false-falsefalse-en-us-x-none.html 